\title{
Murais de ponta-cabeça: reflexões sobre a linguagem e práticas de inversão de sentido
}

\author{
Upside down murals: reflections about the language and practices of inversion of sense
}

Murales al revés: reflexiones sobre el lenguaje y las prácticas de inversión del sentido

\author{
Mateus Pranzetti Paul Gruda* \\ José Sterza Justo
}

\begin{abstract}
Resumo
Ao longo de três anos, observamos e registramos uma experiência de intervenção simples, mas que causou impacto em um campus de uma universidade pública do Estado de São Paulo. Tal experiência ocorreu em um dos prédios desse campus. Como se tratava de um prédio com bastante circulação, havia vários murais para fixação de cartazes, avisos e outros informes. A intervenção consistiu principalmente em inverter o sentido dos cartazes, colocando-os de ponta-cabeça. Tomando essa intervenção como objeto de análise e reflexão, foi possível discutir despotencializações da linguagem impingida por estereotipias e repetições cotidianas no processo de significação, bem como efeitos que rupturas de tais estereotipias geram nas relações sociais e nas produções de subjetividade. Para isso, discutimos como se dão a formação e a manutenção dos sentidos através dos "óculos sociais" e "corredores semânticos", destacando a perspectiva fascista da linguagem denunciada por Barthes e possibilidades de se romper com esta.
\end{abstract}

Palavras-chave: Linguagem. Intervenção social. Polissemia.

\begin{abstract}
During three years, we observed and registered a simple intervention experience, which caused a huge impact in a public University campus, located in São Paulo state. This intervention occurred in one of the buildings of this campus. As this building had a massive circulation of people, there are some murals for posters, notices and other ads. The intervention was mainly about to reverse the sense of the posters, putting these in the upside down position. We analysed and did some reflections concerning that intervention, thinking about disempowerment of language that is foisted
\end{abstract}

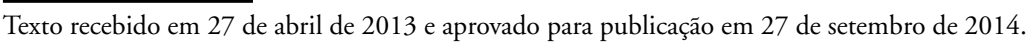

Doutor em Psicologia, Unesp/Assis, bolsista FAPESP, pesquisador estagiário no Centre for Comedy Studies Research, da Brunel University London - bolsa de doutorado sanduíche da CAPES. Endereço: Universidade Estadual Paulista Júlio de Mesquita Filho, Faculdade de Ciências e Letras de Assis. Avenida Dom Antônio, 2100 - Parque Universitário, Assis-SP, Brasil. CEP: 19806-900. E-mail: mateusbeatle@hotmail.com.

** Livre-docente em Psicologia do Desenvolvimento pela Unesp/Assis, docente do Dep. de Psicologia Evolutiva, Social e Escolar da Unesp/Assis. Endereço: Unesp, Campus de Assis. Departamento de Psicologia Faculdade de Ciências e Letras. Avenida Dom Antônio, 2100 - Parque Universitário, Assis-SP, Brasil. CEP: 19806-900. E-mail: justo@assis.unesp.br. 
for daily stereotypes and repetitions in the process of signification, as well as the effects of such disruptions in the stereotypes generated in social relations and in the subjectivity production. To do that, we talked about the process of formation and maintenance of the meanings through the "social glasses" and the "semantic corridors", highlighting the fascist perspective of language denounced by Barthes and the possibilities of subverting that.

Keywords: Language. Social intervention. Polysemy.

\section{Resumen}

Durante tres años, observamos y registramos una sencilla experiencia de intervención, pero que causó enorme impacto en un campus de una universidad pública, ubicada en el Estado de São Paulo. La experiencia ocurrió en uno de los edificios de este campus. Como es un edificio con gran circulación de personas, había varios murales para fijación de carteles, avisos y otros informes. La intervención se resumía, principalmente, a revertir el sentido de los carteles, poniéndolos al revés. Tomando esa intervención como objeto de análisis y reflexión fue posible discutir desempoderamientos del lenguaje impuestos por estereotipos y repeticiones cotidianas en el proceso de significación, así como los efectos que rupturas de esos estereotipos generan en las relaciones sociales y en las producciones de subjetividad. Para eso, discutimos como ocurre la formación y la manutención de los sentidos a través de las "gafas sociales" y los "pasillos semánticos", destacando la perspectiva fascista del lenguaje denunciada por Barthes y las posibilidades de ruptura con la misma.

Palabras clave: Lenguaje. Intervención social. Polisemia.

\section{Introdução}

ntre as tantas realizaçóes facultadas pela linguagem e cultura, tais como a comunicação, o intercâmbio de experiências, a transmissão dos legados de uma geração a outra, colocam-se suas contribuições fundamentais para a cimentação das relações sociais (Sodré, 1992). A organização social, a sintonia das ações individuais, bem como conflitos e divergências, igualmente importantes para a dinamização das relações sociais, dependem da mediação simbólica responsável pela inteligibilidade e decifração dos sentidos que acompanham as produções humanas.

A vida em sociedade mergulha, inevitavelmente, o indivíduo no universo da linguagem e de línguas específicas (códigos compartilhados por agrupamentos 
humanos), que funcionam de maneira paradoxal: por um lado, abrem o horizonte do homem para infinidade de signos, de combinaçôes entre significantes e significados e de encadeamentos entre eles em sequências produtoras de significação; por outro, pode muito bem se prestar a constrições da comunicação e da produção simbólica.

Barthes, em uma de suas frases lapidares, afirmou, de maneira surpreendente na época em que proferiu sua aula inaugural na cadeira de Semiologia Literária no prestigioso Collège de France, mais precisamente em 1977: "A língua, como desempenho de toda linguagem, não é nem reacionária nem progressista; ela é simplesmente: fascista; pois o fascismo não é impedir de dizer, é obrigar a dizer" (Barthes, 2000, p. 13). A surpresa dessa afirmação, feita de maneira tão radical e contundente, está na denúncia do autoritarismo da língua. Porém não daquele conhecido autoritarismo que se vale de instrumentos de proibição, coerção e punição, mas sim de outro tipo de autoritarismo, bastante sutil, que se vale da incitação ao dizer, porém acompanhada de refinados mecanismos de controle do que é dito e de controle e gestão da produção cultural como um todo.

Para Barthes, o simples fato de as línguas terem uma estrutura gramatical e modos de enunciação que designam, obrigatória e previamente, o lugar do sujeito mediante os pronomes pessoais já representaria uma razoável limitação da linguagem e denunciaria seu caráter fascista. Porém, segundo ainda o mesmo autor, apesar disso, não haveria como existir fora da linguagem e restaria, pelo menos como forma de resistência, "trapacear" (Barthes, 2000, p. 15) com a língua, subvertê-la até onde for possível. Para tanto, a poesia seria uma ferramenta poderosa, a saber, não somente a poesia feita pelos poetas, mas toda a poesia, entendida como sublevações, feitas em quaisquer campos, contra ritualizações da linguagem, como pode acontecer no próprio campo da ciência mediante rupturas com cristalizações de sua linguagem.

A linguagem e a produção simbólica, engessadas por formações discursivas associadas à ideologia (Maingueneau, 2008; Orlandi, 1996, 2009), agenciadas pela indústria cultural (Adorno \& Horkheimer, 1997) ou submetidas aos interesses do mercado (Jameson, 2001) expõem outras mordaças, além das estruturais da própria língua, que constrangem, impedem ou domesticam a expressividade humana e a produção de sentido. Linguagem, produção simbólica e cultura assumem, ainda mais na chamada "sociedade da informação" contemporânea (Polizelli \& Ozaki, 2008), uma importância central e em torno delas irão se desenvolver poderes, disputas, hegemonias, controles e políticas e gestão do social e da subjetividade. 
Quaisquer mudanças ocasionadas no conjunto e na estabilidade dos signos, mesmo aquelas mais triviais ou tênues, são capazes de provocar preocupações aos poderes constituídos. Desarranjos no sistema simbólico podem soar como a iminência do caos ou como borrôes que, no mínimo, podem dificultar a visibilidade e o reconhecimento dos signos e dos códigos de leitura familiares e solidificados no e pelo cotidiano.

Blikstein (1995), ao apresentar as diferentes teorias da linguagem, ressalta principalmente aquelas que entendem o signo como tendo uma constituição triádica, formada pelo referente, significante e significado. O referente funcionaria, na constituição do signo, como a porta de entrada das imagens matriciais produzidas pela cultura. Como resultado da práxis, seria, especialmente, sobre o referente que se colocariam os "óculos sociais", os apriorismos da significação responsáveis pelas estereotipias da linguagem. Esse autor chama isso de "padrôes perceptivos", afirmando que, independentemente da denominação (óculos sociais ou padrões perceptivos), eles constituem os "estereótipos de percepção" pelos quais o homem decodifica a realidade e age sobre ela, produzindo socialmente suas condiçõos de existência.

Com base considerações realizadas por Adam Schaff, na obra "Linguagem e Conhecimento", Blikstein (1995) raciocina:

Parece-nos razoável supor que, na dimensão da práxis vital, o homem cognoscente $e^{l}$ desenvolve, para existir e sobreviver, mecanismos não verbais de diferenciação e de identificação: para mover-se no tempo e no espaço de sua comunidade, o indivíduo estabelece e articula traços de diferenciação e de identificação, com os quais passa a discriminar, reconhecer e selecionar, por entre os estímulos do universo amorfo e contínuo do "real", as cores, as formas, as funções, os espaços e tempos necessários à sua sobrevivência. Discriminatórios e seletivos que são, tais traços acabam por adquirir, no contexto da práxis, um valor positivo ou meliorativo em oposição a um valor negativo ou pejorativo; assim é que os traços de diferenciação e de identificação, impregnados de valores meliorativos/pejorativos, se transformam em traços ideológicos. E aqui eclode a semiose: os traços ideológicos vão desencadear a configuração de "fôrmas" ou "corredores" semânticos, por onde vão fluir as linhas básicas de significação, ou melhor, as isotopias da cultura de uma comunidade (p. 60-61, grifos do autor).

Assim, “com os estereótipos gerados pelos corredores isotópicos é que 'vemos' a realidade e fabricamos o referente" (Blikstein, 1995, p. 61-62, grifos do autor). Até aqui, é possível notar que tanto os signos como o processo de significação não são estanques; pelo contrário, são construídos e reproduzidos continuamente

\footnotetext{
Em linhas gerais, na perspectiva marxista (Marx \& Engels, 1984), os conhecimentos teórico e prático não estão dissociados (tal separação produz a ideologia, a qual ocasiona a manutenção dessa divisão). Assim, a consciência humana está relacionada com as relações sociais situadas e condicionadas historicamente, as quais se estabelecem a partir da produção material da vida.
} 
na comunidade dos falantes que desenvolve padrões de percepção, filtrando as imagens primevas do mundo (os referentes) através de seus "óculos sociais".

Segundo Blikstein (1995), a sociedade e a cultura criam "corredores semânticos", nos quais os referentes são perfilados e avaliados de forma positiva ou negativa. Assim, por exemplo, o corredor semântico formado pela "verticalidade" valora diferentes signos associados a esse referente, de maneira que tudo o que representa "estar acima" ou "no alto" tende a ser bem apreciado e o que representa estar "abaixo" tende a ser depreciado. Tais corredores, portanto, além de categorizarem a produção simbólica, atribuem a ela valores por meio dos quais os referentes são posicionados socialmente e inscritos nas relações de poder. Por esse caminho, formam-se também os preconceitos como aqueles que associam ao "negro" sentidos pejorativos e ao "branco" sentidos meliorativos. $\mathrm{Na}$ vala dos corredores semânticos, os signos assumem valores fixos e são submetidos à repetição, à mesmice e à monossemia, vale dizer, cristalizam-se, são mumificados e perdem sua principal propriedade que é a fluidez, o nomadismo, a polissemia e a alimentação da infinitude do processo de significação.

No cotidiano, podemos notar o quanto a percepção estereotipada engessa a linguagem e o pensamento, muitas vezes fazendo com que mudanças simbólicas e de códigos sejam rejeitadas e sentidas como ameaçadoras e inseguras, ainda que sejam mudanças triviais e, ou, despretensiosas.

Relembrando Barthes (2000), a linguagem é ambígua: usualmente assume um caráter restritivo, coercitivo e dominador por impor formas e conteúdos ao dizer e às expressões do homem; mas ela também faculta a polissemia e a criação, admitindo escapes ou trapaças com seus próprios convencionalismos. É nas brechas do processo de significação ou nos "delírios" possibilitados pela linguagem que o sujeito pode se constituir como ator/autor, intercedendo ativa e criadoramente no seu mundo. "Delírios" entendidos aqui no sentido etimológico da palavra, ou seja, como aquilo que escapa ou transborda dos sulcos cavados na terra. Desse modo, estamos entendendo como delírio, na linguagem, aquilo que escapa aos corredores semânticos e às isotopias. É precisamente com esse sentido que compreendemos a intervenção semiótica descrita adiante, a qual é o objeto de estudo deste nosso artigo. 


\section{Princípios e procedimentos metodológicos}

\section{Intervenções}

Os processos de intervenção podem ser compreendidos com base nos distintos campos teórico-práticos em que se realizam e se norteiam (Machado, 2010). Podemos falar de intervenções psicossociais, artísticas, de intervençóes médicas, de intervenções envolvendo várias vertentes da Psicologia, de intervenções pedagógicas, entre outras tantas da enorme gama de possibilidades de se intervir. Seguindo uma acepção genérica, os processos de intervenção foram e são historicamente entendidos como uma forma de modificar as relações sociais estabelecidas, propondo ou estimulando a construção de novos olhares acerca das realidades vivenciadas.

Por um longo período, tais intervenções foram realizadas, exclusivamente, em espaços delimitados, com práticas localizadas e específicas. Isso ocorreu tanto no campo da arte (por exemplo, as instalaçóes e outros tipos de arte inseridos nas galerias e museus) quanto no campo das açóes sociais promovidas pelo poder público e por outras organizaçōes, envolvendo diversas profissões e disciplinas científicas (Psicologia, Arquitetura, Medicina, Serviço Social, entre outras). A partir de meados da década de 60 do século XX, essas práticas passaram a romper fronteiras e se difundiram mais fortemente pelo espaço das cidades como um todo (Barja, 2008).

A arte urbana, como o grafite nos muros e demais edificações públicas, em trens, calçadas e tudo mais que compóem paisagens/cenários urbanos, é bom exemplo de como as intervençóes se inscrevem no espaço coletivo, produzindo rupturas ou realizando denúncias das estereotipias que se espalham por toda cidade. Questionam também o estatuto privado da produção artística e ousam transgredir leis e padronizações estéticas ao se rabiscar, desenhar, escrever de forma não convencional naquilo que é proibido (as fachadas dos prédios públicos, as calçadas, os monumentos e outros objetos do espaço urbano). $\mathrm{O}$ artista/grafiteiro anônimo Banksy (2012), por exemplo, pontua, em seu livro "Guerra e Spray", sua intenção, dentre outras, de se contrapor ao uso abusivo e privativo dos espaços públicos pelo capital via indústria da propaganda visual.

De um modo geral, "a arte urbana é vista como um trabalho social, um ramo da produção da cidade, expondo e materializando suas conflitantes relações sociais" (Pallamin, 2000, p. 20). Dentro dessa concepção, também podemos citar e incluir o chamado "terrorismo poético", descrito por Hakim Bey, o qual abarca intervençôes diversas em locais públicos, tais como: "poemas rabiscados nos lavabos dos tribunais, pequenos fetiches abandonados em parques e restaurantes, 
arte-xerox sob o limpador de para-brisas de carros estacionados, slogans escritos com letras gigantes nas paredes de playgrounds [...]” (Bey, 2003, p. 6).

Uma característica central, comum e inerente a tais modos de intervir, é a atitude de indiferença em relação à autoria. Os grupos podem ser identificados por alguma marca singular, mas a identificação individual dos componentes não é somente desnecessária, é conscientemente refutada por aqueles que intervêm. Para eles, o importante, de fato, são açôes e, principalmente, seus desdobramentos.

Tais manifestações artísticas como essas que se expressam sorrateiramente ou clandestinamente nos espaços urbanos podem ser consideradas como "arte menor" (Lima, 2006) ou como "arte resistência", no sentido de que se constituem como forças micropolíticas de afrontamento à Biopolítica e ao encaixe da existência no regime da acumulação de mercadorias (André, 2011) ou em forças de resistência à opressão e ocupação militar, ou a regimes ditatoriais que se abatem sobre povos e países (Tripp, 2012). No entanto, é preciso ponderar, nem tudo aquilo que é chamado de "arte" (sobretudo hoje, quando limites são tênues e flexíveis) assume um caráter de insurgência, contestação e afrontamento aos poderes hegemônicos. Em contrapartida, também seria um equívoco entender a ciência como estando automaticamente alinhada a forças conservadoras, submetida à lógica do capitalismo e do mercado. Parcelas da arte podem funcionar a favor dos poderes hegemônicos e, por outro lado, a ciência e os ambientes onde ela é cultivada, como no caso das universidades, podem muito bem funcionar, também em parte, como enfrentamento e resistência a tais poderes.

Nesse sentido, relembremos Barthes (2000) quando ele afirma que a subversão da linguagem não é somente possível na arte, na poesia, mas em qualquer outro tipo de linguagem, inclusive a científica. Dessa forma, encontramos na academia, em particular, situações de extrema rigidez semiótica, tais como essa que será aqui tomada como objeto de análise, quanto situaçóes de ruptura radical com estereotipias de linguagem e semioses cristalizadas, como são tantos casos de aulas bastante criativas e inventivas, pesquisas e publicações científicas revolucionárias, e assim por diante.

\section{Descrição da experiência de intervenção analisada}

\section{Local}

A intervenção alvo de nosso relato de observação foi realizada em um pequeno campus de uma universidade pública, situado no interior do Estado de São Paulo. Entretanto, antes de prosseguirmos, é necessário fazer um apontamento acerca da expressão "campus de uma universidade pública”. As inscrições desta nos 
corredores semânticos e suas visualizações pelos “óculos sociais" da nossa cultura sugerem, a priori, alguns significados, tais como local de reflexão, discussão, criação, arejamento das ideias; lugar de liberdade de pensamento, de flexibilidade e assim por diante. Destarte, em tese, deveria ser um lugar aberto à manifestação do incomum, do estranho e do não familiar.

O campus em questão é relativamente pequeno, frequentado cotidianamente por alunos, docentes e funcionários. Tem cinco cursos de graduação, sendo três da área de Ciências Humanas, um da área de Biologia e outro de Engenharia. Mesmo eventuais frequentadores não vinculados organicamente à universidade estão familiarizados com os signos que aí existem e reconhecem toda a linguagem produzida em cada lugar específico: as seções administrativas, as secretarias, as salas de aula, a sala de cada professor, do diretor, a biblioteca, os corredores, os murais de avisos e outros nichos existentes em um campus universitário. É nesse contexto que precisa ser situada e entendida a intervenção que foi aí realizada e que será tomada como objeto de nossas reflexões.

\section{Duração}

As intervençôes ocorreram durante aproximadamente três anos e de maneira quase que ininterrupta (exatamente entre os anos de 2006 e 2008). Tais intervenções consistiam em mudanças sistemáticas na disposição de mobiliários de uso coletivo (sofás, bancos e poltronas existentes nos saguões dos prédios), nos murais e na disposição das placas de sinalização e de indicação das salas. Móveis eram trocados de lugar, e cartazes e placas de identificação das salas, principalmente aquelas que continham os nomes dos professores, eram colocados "de ponta cabeça". Nenhum dano foi registrado. Apenas se invertia a posição dos cartazes, placas e dos mobiliários de uso comum que existiam nos corredores e saguão dos prédios. Após algum tempo, um grupo, apenas identificado pela sigla MRKC, passou a assumir a autoria de algumas dessas açôes. E, do mesmo modo que estas se iniciaram, sem justificativas ou explicações por parte de seus autores, foram encerradas.

\section{Participantes}

Segundo declarações dos entrevistados, o grupo MRKC se formou espontaneamente e era composto por estudantes do campus em que transcorreram as intervenções, objeto de nosso estudo neste texto. No início, segundo comentários de um dos participantes que esteve presente durante o período todo em que as intervenções ocorreram, o grupo era formado por apenas quatro estudantes e iniciou tais ações sem qualquer intuito predefinido, a não ser 
subverter pequenas ordens e estereotipias existentes nos prédios da universidade. $\mathrm{E}$, ante o feedback que indiretamente notaram, como as queixas escutadas pelos corredores, decidiram prosseguir realizando as diversas inversões de sentido as quais serão detalhadas ao longo deste artigo.

Aos poucos, segundo os entrevistados, mais estudantes foram se somando à inciativa, alguns que se conheciam e outros completamente anônimos. Cinco deles, vinculados aos cursos da área de Ciências Humanas, se reconheciam, porém apenas três planejaram (em períodos distintos) a maioria das intervenções e outros também realizavam suas açôes no completo anonimato: sequer foram identificados pelos integrantes "oficiais" do grupo, não sendo possível, segundo eles, saber quantos eram.

Realizamos entrevistas coletivas com dois dos estudantes que se assumiam como alguns dos criadores do MRKC. Vale esclarecer que tais integrantes desse grupo se identificaram para nós e se assumiram, espontaneamente, como criadores desse movimento, mas se mantiveram sempre em total anonimato e sigilo perante a comunidade universitária. Também assumimos com eles, durante o contrato para a realização da pesquisa, o compromisso de manter o total sigilo em relação a suas identidades.

As entrevistas foram realizadas em uma saleta de um dos prédios do campus, suficientemente isolada para assegurar a privacidade da situação e as condições adequadas para esse tipo de atividade. Ao todo, foram realizadas quatro entrevistas/encontros, todas com a presença dos dois participantes/membros do MRKC, nos últimos seis meses da intervenção, portanto durante o segundo semestre do ano de 2008. Os participantes eram solicitados a relatar livremente a experiência de intervenção: não havia tempo para cada um nem regras para o uso da palavra. $\mathrm{O}$ entrevistador intervinha para pedir esclarecimentos ou para redirecionar a conversa para o assunto principal ou, ainda, para perguntar sobre aspectos da intervenção não mencionados nas falas dos participantes.

As observações foram feitas, espaçadamente, nos locais da intervenção, ao longo de todo o período de sua duração. No início, tais observações foram feitas de forma assistemática e, no último ano, com a decisão de realizar uma pesquisa sobre o assunto, passaram a ser regulares e sistemáticas. Foram registrados o tipo de intervenção realizada, mediante descrições pormenorizadas, e a reação dos transeuntes, quando ocorriam (deter-se diante das intervençôes, sorrir, demonstrar irritação, demonstrar concordância, discordância ou descontentamento, como normalmente se faz com meneios de cabeça; fazer comentários sob a forma com pessoas ao lado ou de solilóquios, entre outros tipos de reação). Sempre que uma nova intervenção ocorria, fazia-se o registro. Cabe esclarecer que os pesquisadores 
frequentavam diariamente esse campus, tornando possível a observação de cada intervenção.

Registro e forma de organização das informações obtidas

As entrevistas foram gravadas e as observações foram registradas, de maneira cursiva e por escrito, mediante anotaçóes feitas no momento do acontecimento e, posteriormente, a elaboração de relatos completos e lapidados. O observador não se identificava como tal nas situaçôes observadas e nem interagia com os observados.

As entrevistas foram ouvidas, repetindo-se trechos, quando necessário. Os conteúdos foram selecionados, de acordo com os objetivos da pesquisa, privilegiando-se os seguintes temas: tipo de intervenção, estratégias de ação, recursos utilizados, objetivos e intenções, resultados esperados e avaliação do impacto. Tais categorias temáticas foram estabelecidas a posteriori. Não houve transcrição integral das entrevistas, apenas foram registrados trechos de falas e o sentido do que foi dito, segundo a compreensão do entrevistador/ouvinte, dentro das categorias estabelecidas.

Síntese dos acontecimentos registrados pelas entrevistas e observações

De imediato, observando e escutando o que se dizia sobre tais inversões, pudemos constatar certo desconforto de boa parte da comunidade interna e externa frequentadora do local. Pelos corredores, muitos se queixaram verbalmente dos atos, outros se irritavam e desfaziam as inversões.

Alguns professores sentiram como um desrespeito terem seus nomes colocados de ponta cabeça na porta de suas salas. Um deles, inclusive, utilizou as mais diversas técnicas para evitar a inversão: imprimiu seu nome nos dois sentidos, de cima para baixo e vice-versa; pregou tachinhas em todo o limite da folha com seu nome na porta de sua sala; até afixou um bilhete escrito "deixem de criancice e venham falar comigo". Outro professor, durante uma de suas aulas, qualificou os atores daqueles atos como "doentes" e "desocupados". O chefe de um dos departamentos sugeriu aos colegas que fosse aberta uma sindicância para apurar a autoria e as responsabilidades por aqueles atos. Vários alunos também expressaram algum incômodo. A maioria manifestava uma posição contrária àquelas intervençôes, porém sem repudiá-las com a mesma veemência demonstrada por alguns integrantes dos corpos docente e de funcionários. 
Alguns pequenos acontecimentos deflagrados em torno dessas intervenções também demonstraram os efeitos que geraram. Houve o caso de um professor que utilizou inúmeras técnicas para impedir que seu nome ficasse de ponta-cabeça na porta de sua sala. Ao longo da "batalha" travada entre docente e MRKC, acabou acontecendo um diálogo cego ${ }^{2}$ entre ele e os manifestantes anônimos, uma vez que cada investida do docente correspondia a respostas inesperadas, chegando ao ponto de se comunicarem via bilhetes afixados na porta da sala dele: o docente colou um recado em post it, solicitando uma conversa, e o grupo replicou, em papel higiênico, deixando campos em branco para que o docente preenchesse $o$ local e o horário que melhor lhe conviesse para que promovessem a reunião. Um diálogo inusitado, levado a cabo por meios pouco convencionais e realizado em um espaço micropolítico, tal como se configuram, hoje, os embates de poder.

Outro diálogo cego curioso ocorreu por meio de pichações. $\mathrm{Na}$ parede de um dos banheiros, foi travada uma longa discussão sobre as atitudes que estavam sendo tomadas, e a cada comentário novo de alguém havia sempre uma resposta do grupo alimentando (e retroalimentando) o debate. Tratava-se de ações descontínuas e fragmentadas no tempo, tomadas por pessoas distintas, mas todas compondo um intertexto resultante da abertura do "diálogo" para qualquer participante, sem qualquer regra, facultando até mesmo a possibilidade de um mesmo participante fazer a réplica do seu próprio argumento.

A troca de lugar da mobília dos corredores gerou dois episódios interessantes que merecem nosso destaque. Um deles consistiu na transferência de um jogo de sofás, localizado próximo à secretaria de um departamento, para um saguão em frente às salas de aula. Tal mudança permaneceu somente por cerca de quatro horas, pois o chefe do departamento da respectiva secretaria, tomando a ação como uma afronta à sua seção, ordenou que os funcionários da limpeza desfizessem imediatamente a troca de lugar.

Outra situação pitoresca ocorreu quando os anônimos que realizavam tais intervençôes resolveram, como mais uma delas, fazer de um dos banheiros do prédio um escritório para o seu "movimento". Transferiram os vasos de plantas do corredor, uma mesa e algumas cadeiras de uma das salas de aula para dentro do espaço do banheiro, além de picharem a parede de entrada ("Bem-vindos ao Escritório do MRKC”). As portas de cada compartimento de vasos sanitários foram identificadas como se fossem repartições do escritório: Refeitório, Sala de Reuniōes, Assessoria de Imprensa e Assessoria Jurídica. A ironia maior ficou por conta de identificarem o ralo existente neste banheiro como sendo a "Ouvidoria" do movimento.

\footnotetext{
Empregamos o termo "cego" para pontuar que os interlocutores não se conheciam face a face, tal como é utilizado na linguagem científica, especialmente em situação de avaliação de projetos ou artigos submetidos para publicação, as quais são chamadas por "avaliação cega por pares" ou "duplo cego".
} 
Esse escritório, por assim dizer, foi desfeito pelos funcionários da limpeza e refeito pelo grupo uma série de vezes; aliás a persistência era outra característica notável e intrigante dessas ações: refaziam constantemente suas intervenções, sempre desfeitas pelos funcionários da limpeza ou por outros usuários do prédio.

Embora a modificação espacial da mobília e cartazes respondesse pela maior parte dos atos, qualquer acontecimento novo e diferente no ambiente do campus, por mais fortuito e singelo que fosse, era atribuído ao MRKC. Uma ação menos visível e identificada com aquelas que caracterizavam o grupo era a constante apropriação que faziam das mais diversas realizações, como no caso da reunião solicitada pelo docente em que se colocaram como os responsáveis pela necessidade de um encontro. Qualquer obra de infraestrutura no campus, organização de eventos, avisos em geral, regulamentações, convocações, entre outros, logo recebiam uma inscrição de autoria, apoio ou repúdio ao MRKC. Contíguos aos materiais divulgados nos murais foram colocadas frases tais como "O MRKC se responsabiliza por tal ato" ou então "O MRKC repudia tal ato". Usualmente, as manifestações de apoio, de repudio ou de reivindicação de autoria eram colocadas em materiais de natureza bem distinta (como papel de embrulhar pão ou papel higiênico, por exemplo) o que, normalmente, gerava incoerências e, ou, contradiçõos e tornava o enigmático $\mathrm{MRKC}$ ainda mais obscuro por não assumir uma identidade definida.

\section{Análise e reflexão}

Mesmo no breve relato da intervenção em tela, é possível notar que ela foi capaz de criar certo impacto e perplexidade. Os cartazes de ponta-cabeça nos murais, assim como as tabuletas de sinalização do prédio; as mudanças na disposição do mobiliário; a instalação de um pretenso escritório no banheiro; a inversão entre as placas de masculino e feminino nas portas de acesso aos sanitários, entre outras açôes, tiveram uma forte ressonância sobretudo no plano subjetivo.

As dificuldades, de ordem prática, para a leitura dos cartazes de ponta-cabeça ou para se usar um banheiro com plaquetas de identificação não usuais - as placas de identificação do gênero (masculino e feminino), afixadas nas portas, não correspondiam àquelas estabelecidas havia muito tempo - não foram o único e, talvez, nem o principal transtorno gerado por esse tipo de intervenção. Mais do que isso, foi possível observar irrupções de sentimentos e afetações que diziam respeito a incômodos, preocupações e até reações de ira que, manifestadamente, tinham como fonte o anonimato dos autores da intervenção e o desconhecimento de seus objetivos e propósitos. 
Uma pergunta muito comum que se ouvia nos corredores e até mesmo em reuniōes dos colegiados era: o que significa isso? A insistência dessa pergunta e a especulação por respostas que dessem algum sentido e inteligibilidade àquelas intervençôes sugeriam que a preocupação maior era com o anonimato dos autores e com os enigmas que revestiam aqueles atos. Tratava-se de uma "coisa" que resistia à significação, que não se enganchava em significados prontos e estabelecidos; um novo referente que ali se despontava e que escapava aos usuais e conhecidos, que escapava às lentes dos "óculos sociais" as quais impediam os frequentadores do prédio, transformado em lugar familiar pela rotina, de verem as coisas de outros modos, de reconhecerem nesse espaço outros referentes.

Os cartazes nos murais, por exemplo, podiam nem ser interessantes ou até frequentemente ignorados devido ao seu número excessivo, à sua própria desorganização dentro do espaço dos murais pela sobreposição de uns sobre os outros, ou mesmo pela desatualização de boa parte deles, porque os antigos não eram removidos. Porém a simples inversão de orientação (parte de cima para baixo), modificando o convencional e esperado de um cartaz, tornaramnos chamativos e indecifráveis. Presenciamos muitos indagando: "qual o sentido de virar de ponta-cabeça?”. Protesto? Falta do que fazer? Traquinagem? Essas e muitas outras especulaçôes foram feitas, e uma infinidade de hipóteses veio à tona, seguramente como modo de aliviar a ansiedade ou de satisfazer minimamente a curiosidade.

Mesmo as pichações mais reservadas, como aquelas feitas nos banheiros, foram objetos de controvérsias. Houve quem protestasse, afirmando que os banheiros tinham sido pintados há pouco, argumento prontamente refutado por um dos alunos: "Banheiros sempre foram pichados e sempre o serão".

As intervençôes realizadas pelo grupo também se assemelhavam aos chamados happenings - acontecimento breve, inesperado, (por vezes) superficial. Como exemplos, temos os chamados flash mobs ou as intervenções gráficas e urbanas realizadas por Banksy (2012), uma vez que, mesmo tendo se prolongado por um tempo considerável, não eram extremamente regulares e não obedeciam a um cronograma preestabelecido. Não havia hora ou dia certos para acontecer. Em algumas semanas, ocorriam várias intervenções; enquanto em outras, nada acontecia. Assim, tanto a imprevisibilidade quanto a surpresa eram parte da produção de sentido.

A questão principal de toda essa intervenção semiótica diz respeito à potência da linguagem como instrumento de estabilização de percepções e entendimento do mundo, como disparadora de sentimentos, de afetos, de emoções e, sobretudo, de ansiedades confusionais, quando as estereotipias são rompidas. Os 
exemplos que descrevemos da situação analisada vão ao encontro do que Barthes (2000) denunciou, de maneira bastante radical, como o efeito dominador da linguagem, quando afirmou categoricamente que a linguagem é fascista, não exatamente por interditar, mas por obrigar a dizer dentro do convencionalismo e de uma dada gramática da língua. $\mathrm{O}$ caso que apresentamos mostra a operação de uma "gramática simbólica" dada a priori, que organiza a experiência do espaço. Cada coisa já tem seu lugar, e cada espaço somente deve ser ocupado por objetos devidamente categorizados e destinados a ele. Isso cria um sentido de familiaridade, estabilidade, estagnação, ordem e pureza, acompanhado de práticas de repetição e reprodução.

Blikstein (1995) reporta-se às isotopias e constrições da linguagem na prática cotidiana primeva, na qual o homem assegura suas condiçóes básicas de existência:

A impossibilidade de capturar a semiose não verbal, que se desencadeia na dimensão oculta entre a práxis e o referente, compele o indivíduo a recorrer ao sistema verbal para materializar e compreender a significação escondida. Assim, a língua passa a atuar sobre a práxis, os corredores isotópicos e os estereótipos perceptuais; [...] Agindo sobre a práxis, a língua também pode modelar o referente e "fabricar" a realidade. [Além disso] [...] nessa interação língua/práxis, instala-se uma reiteração circular que, em princípio, não pode ser rompida: a práxis cria a estereotipia de que depende a língua e esta, por sua vez, materializa e reitera a práxis (p. 79-80).

Dessa forma, tanto a cognição quanto a decodificação da linguagem estariam ambas sujeitadas:

[...] a um processo ininterrupto de estereotipação, a ponto de consideramos real e natural todo um universo de referentes e realidades fabricadas. Daí a função fascista da linguagem, segundo a expressão de R. Barthes. A língua "amarra" a percepção/cognição, impedindo o indivíduo de ver a realidade de um modo ainda não programado pelos corredores de estereotipação; como Sísifo, estaríamos condenados a conhecer, ou a reconhecer, sempre a mesma realidade: nossas retinas "fatigadas" estariam condenadas a ver sempre a mesma "pedra no meio do caminho" de Carlos Drummond de Andrade. Em seu "amarramento" com a práxis, a língua adquire uma função fática compensatória: quando não compreendemos a realidade, utilizamos os estereótipos verbais para reiterar o referente ou a realidade fabricada por nossos corredores isotópicos (Blikstein, 1995, p. 82, grifos do autor).

O efeito de retorno da linguagem no reforço das estereotipias que engessam a percepção da realidade a tornam um importante instrumento de naturalização 
e de estabilização das decodificações e das ações do ser humano no seu mundo. Cartazes afixados em murais, como no caso que estamos analisando, são tomados como "naturais" como se sempre tivessem sido assim e não houvesse outra forma de ser. A percepção já está mais do que programada para buscar cartazes em murais e não em outro lugar e, mais ainda, ela está evidentemente à espera de que o cartaz esteja devidamente afixado na posição vertical e com o texto escrito linearmente da esquerda para a direita e de cima para baixo. É nesse tipo de imposição da linguagem, imposição de um contexto conversacional (no caso, o mural, o local destinado a ele), imposição de normas e regras rígidas para a produção da semiose (a posição do cartaz, seu alinhamento, a direção do texto e a própria gramática) que Barthes (2000) localiza a presença mais forte do fascismo: o fascismo exercido na constrição do dizer, na restrição da polissemia.

O profundo sentido de ordem, de disciplina, de sujeição e submissão, que está na base da linguagem, alimentada pelas estereotipias, passa completamente despercebido na pirotecnia da superfície, a qual põe em evidência uma profusão de signos devidamente estetizados, como ocorre com cartazes que usam recursos sofisticados de diagramação e imagem. A quantidade de informação que geralmente circula nesses espaços (murais das universidades) sugere uma ampla liberdade de comunicação e expressão encobridora da presença de fortes estereotipias presentes na forma de dizer e no contexto que circunda a conversação e participa ativamente de produção de sentido.

A força de tais estereotipias perceptolinguísticas é tão avassaladora que impede o reconhecimento de sua presença e bloqueia qualquer crítica ou questionamento. Por exemplo, as intervençóes que estamos tomando como objeto de análise foram amplamente recriminadas como "ato de molecagem", "vagabundagem", "perturbação" e até mesmo de "vandalismo". Embora, segundo os participantes, não houvesse nenhum objetivo claro e determinado por parte deles, como a promoção de novos "corredores isotópicos", as alterações que realizaram não geraram, nos habitantes daquele espaço, questionamentos das convenções e estereotipias ali estabelecidas (murais, disposição do mobiliário, entre outras), pelo menos que fossem explícitos e pudessem ser notados. O que se observou, com bastante frequência, foram sentimentos de invasão, intrusão e repúdio ao que era considerado como açôes de violência simbólica e açôes autoritárias. Inclusive, quando as intervenções cessaram, foi possível observar uma sensação de alívio com o retorno à "tranquilidade" cotidiana do lugar, como se nada tivesse acontecido. 


\section{Considerações finais}

As análises realizadas sobre a intervenção semiótica, aqui tomada como objeto de análise e reflexão, colocaram em evidência o confronto entre práticas de linguagem normativas, estabilizadoras, reprodutoras, monossêmicas, típicas de regimes autoritários, e práticas de linguagem insurgentes, desconstrucionistas e polissêmicas, típicas de regimes libertários ou de discursos lúdicos, tal como entende Orlandi (1996) o modo de produção de sentido no qual a fala circula livremente entre os interlocutores e não há a preocupação com o controle do referente.

O uso de categorias fechadas, delimitadas e determinadas, tanto quanto a produção de sentidos constritos, eternos, estanques e dados a priori estão em consonância com práticas coercitivas ou impositivas da linguagem, em um aparente desacordo com a explosão da linguagem, da comunicação e da produção simbólica desse nosso tempo em que se apresenta como mais flexível, mutante, horizontalizado e, sobretudo, prenhe de tecnologias que possibilitam a expansão e celeridade da cultura. A universidade pode ser tomada como um lugar onde valores relacionados à autonomia, liberdade, criação e ousadia, assim como as tecnologias atuais de produção simbólica e de comunicação encontramse bastante presentes e ativas. Contudo nem ela consegue acolher rupturas de estereotipias de linguagem e de comunicação profundamente enraizadas e estabelecidas.

A aparente explosão da semiose na atualidade vem acompanhada de controles e gestôes da linguagem e da produção de sentido bastante refinados. A chamada sociedade da informação e das mídias (Polizelli \& Ozaki, 2008), por certo, expande as relaçóes entre as pessoas, o contato entre culturas, o intercâmbio entre as línguas, possibilita a profusão simbólica, porém, de maneira bem administrada, seja pela chamada indústria cultural (Adorno \& Horkheimer, 1997) ou pelo semiocapitalismo, tal como Bifo (2007) designa a transformação do signo em mercadoria, na atualidade.

Junto aos macropoderes, derivados das forças econômicas, podemos acrescentar micropoderes que atuam no cotidiano e que se valem, ainda, de forças psicológicas e subjetivas. No acontecimento que analisamos, a perplexidade, os receios e os temores suscitados pela inversão de imagens cristalizadas no cotidiano de uma instituição mostram o quanto a poluição de signos, tal como a grande quantidade de cartazes num mural, por si, não implica em expansão da linguagem, da produção de sentido ou da semiose. Traços básicos de significação, corredores semânticos, agenciamentos de enunciação, óculos sociais e compulsividades empregadas no processo de significação, enfraquecem 
a linguagem, impõem a ela a mesmice e a reprodução, reduzindo ou anulando sua potência criadora e de transformação. No semiocapitalismo (Bifo, 2007) ou na produção e consumo excessivos de signos, a grande oferta de imagens e de informaçãao, como é o caso da poluição de cartazes em murais de universidades, reforçam repetições e cristalizações, gerando "poluições dromosféricas", como diz Virilio (1993) e poluições da infosfera, mediante acelerações da circulação do mesmo, de produtos duplicados, no frenético mercado da semiose.

$\mathrm{Na}$ profusão de autorias reais ou forjadas, as intervenções semióticas aqui analisadas colocavam em xeque a singularidade das mensagens dos murais e suas origens. Denunciavam a mesmice, a padronização dos meios e dos conteúdos das mensagens e a reprodução que esmaecem a autoria e transformam o autor em mero copista.

Em suma, o acontecimento que tomamos como objeto de análise de uma experiência permite reiterar a importância da linguagem no cotidiano, sobretudo daquela que se coloca como trivial, despretensiosa ou comezinha, tal como ocorre com a semiose que emana da disposição de mobiliários e cartazes num mural. $\mathrm{Na}$ aparente racionalidade prática e técnica de isotopias de linguagem, imiscui-se a produção de estereotipias de percepção e da produção de monossemia. Murais e cartazes corriqueiros, aparentemente inofensivos, com uma função meramente prática de informar (veículos de comunicação banais) carregam consigo poderosas lentes de modelação das percepções e da leitura do mundo. Tanto é que simples desarranjos nessas estereotipias semióticas presentes em espaços e objetos secundários, dentro de uma instituição, são capazes de fazer irromper fortes sensações de caos e desordem, e sentimentos persecutórios. 


\section{Referências}

Adorno, T. W. \& Horkheimer, M. (1997). Dialética do esclarecimento: fragmentos filosóficos. G. A. de Almeida (Trad.). Rio de Janeiro: Jorge Zahar.

André, C. (2011, julho, dezembro). Arte, biopolítica e resistência. Revista Brasileira de Estudos da Presença, 1(2), 426-442.

Banksy (2012). Guerra e spray. R. Durst (Trad.). Rio de Janeiro: Intrínseca.

Barja, W. (2008, julho, dezembro). Intervenção/terinvenção: a arte de inventar e intervir diretamente sobre o urbano, suas categorias e o impacto no cotidiano. Revista Ibero-americana de Ciência da Informação, 1(2), 213-218.

Barthes, R. (2000). Aula. L. Perrone-Moisés (Trad.). São Paulo: Cultrix.

Bey, H. (2003). Caos: terrorismo poético e outros crimes exemplares. P. Decia \& R. Resende (Trad.). São Paulo: Conrad.

Bifo, F. B (2007). Generación post-alfa: patologias e imaginarios en el semiocapitalismo. D. Picotto et al. (Trads.). Buenos Aires: Tinta Limón.

Blikstein, I. (1995). Kaspar Hauser ou a fabricação da realidade. São Paulo: Cultrix.

Jameson, F. (2001). A cultura do dinheiro: ensaios sobre a globalização. M. E. Cevasco \& M. C. de Paula (Trads.). Petrópolis: Vozes.

Lima, M. F. A. (2006, julho, dezembro). Por uma arte menor: ressonância entre arte, clínica e loucura na contemporaneidade. Interface, 10(20), 317-329.

Machado, M. N. M. (2010, agosto, dezembro). Intervenção psicossociológica, método clínico, de pesquisa e de construção teórica. Pesquisas e Práticas Psicossociais, 5(2), 175-181.

Maingueneau, D. (2008). Análise de textos de comunicação. C. P. de Souza e Silva \& D. Rocha (Trads.). São Paulo: Cortez.

Marx, K. \& Engels, F. (1984). A ideologia alemã. (4a ed.) J. C. Bruni \& M. A. Nogueira (Trads.). São Paulo: Hucitec.

Orlandi, E. P. (1996). A linguagem e o seu funcionamento: as formas do discurso. Campinas: Pontes. 
Orlandi, E. P. (2009). Análise do discurso: princípios e procedimentos. (8a ed.). Campinas: Pontes.

Pallamin, V. M. (2000). Arte urbana: São Paulo: regiāo central (1945-1998): obras de caráter temporário e permanente. São Paulo: FAPESP.

Polizelli, D. \& Ozaki, A. (Orgs.). (2008). Sociedade da informação: os desafios da era da colaboração e da gestão do conhecimento. São Paulo: Saraiva.

Sodré, M. (1992). A comunicação do grotesco: introdução à cultura de massa no Brasil. Petrópolis: Vozes.

Tripp, C. (2012). The art of resistance in the Middle East. Asian Affairs, 43 (3), 393-409.

Virilio, P. (1993). O espaço crítico: e as perspectivas do tempo real. P. R. Pires (Trad.). Rio de Janeiro: 34. 